\title{
Lotus japonicus LjKUP Is Induced Late During Nodule Development and Encodes a Potassium Transporter of the Plasma Membrane
}

\author{
Guilhem Desbrosses, Claudia Kopka, Thomas Ott, and Michael K. Udvardi \\ Max Planck Institute of Molecular Plant Physiology, Am Mühlenberg 1, 14476 Golm, Germany \\ Submitted 3 November 2003. Accepted 13 February 2004.
}

\begin{abstract}
The KUP family of potassium transporters in plants is large but poorly characterized. We isolated and characterized the first KUP transporter from a legume, LjKUP of Lotus japonicus. Although expressed throughout plants, LjKUP transcript levels were highest in nodules. Induction of $L j K U P$ expression occurred late during nodule development, at a time of rapid organ expansion. A high level of LjKUP expression was maintained in mature, full-sized nodules. However, induction of $L j K U P$ expression was independent of symbiotic nitrogen fixation (SNF), and occurred in ineffective nodules resulting from mutations in either the plant or its microsymbiont, Mesorhizobium loti. Heterologous expression of LjKUP in Escherichia coli showed that the protein is able to transport potassium. Transient expression of a GFP-LjKUP fusion protein in Arabidopsis cells indicated a plasma membrane location for the transporter. Taken together, the results indicate that $\mathrm{LjKUP}$ is a potassium transporter of the plasma membrane, which may play roles in cell expansion during nodule development and in ion homeostasis during SNF.
\end{abstract}

Additional keywords: ion transporter, real-time RT-PCR.

Symbiotic nitrogen fixation (SNF) in legumes takes place in specialized organs called nodules that develop from cortical cells of the root or stem following contact with soil rhizobia. The biological success of SNF rests upon the mutually beneficial exchange of reduced carbon from the plant for reduced nitrogen from the bacteria (Udvardi and Day 1997). Following a series of preliminary signal exchanges (Long 2001; Schultze and Kondorosi 1998; Stougaard 2000), rhizobia enter root-hair and underlying cells via an infection thread produced by redirection of cell wall synthesis (Brewin 1993; Rae et al. 1992). Rhizobia eventually are released from infection threads into cortical cells via endocytosis, which leaves the bacteria surrounded by a membrane of plant origin, called the symbiosome membrane (SM) (Verma and Hong 1996). Growth and division of rhizobia, matched by synthesis of new SM, continues until thousands of symbiosomes, each containing one or more bacteria, fill the infected cells. Rhizobia within symbiosomes eventually differentiate into nitrogen-fixing bacteroids as the physiological conditions of the developing nodule change. Nodule development also is

Corresponding author: M. Udvardi; E-mail: udvardi@mpimp-golm.mpg.de

The complete LjKUP cDNA sequence data is available in the GenBank database under accession number AY359855. accompanied by a reprogramming of plant metabolism, which becomes specialized for the provision of reduced carbon and other nutrients to the bacteroids, and for the assimilation of ammonium and other nitrogen compounds from the bacteroids (Day et al. 2001; Lodwig et al. 2003; Udvardi and Day 1997).

Transporters play integral roles in nodule development and SNF (Udvardi and Day 1997). During nodule development, transporters deliver and distribute ions and metabolites for cell growth and division. This includes transporters in the plasma membrane (PM) that lines the infection thread and in the SM, which together provide nutrients to the growing population of bacteria. Within a mature, nitrogen-fixing nodule, transporters in the SM play a central role in providing energy in the form of malate to the bacteroids, and in removing the products of nitrogen fixation, including ammonium, from the symbiosomes (Tyerman et al. 1995; Udvardi et al. 1988). Transporters of the SM that have been characterized at the biochemical or biophysical level include a P-type $\mathrm{H}^{+}$-ATPase (Campos et al. 1996; Fedorova et al. 1999); a dicarboxylate transporter (Udvardi et al. 1988); $\mathrm{NH}_{4}^{+}, \mathrm{K}^{+}$, and $\mathrm{Ca}^{2+}$ channels (Roberts and Tyerman 2002; Tyerman et al. 1995); an iron transporter (LeVier et al. 1996; Moreau et al. 2002); a Ca ${ }^{2+}$-ATPase (Andreev et al. 1999); and one or more inorganic ion transporters (Udvardi et al. 1991). A number of genes encoding SM proteins also have been cloned: nodulin 26, an aquaporin (Rivers et al. 1997; Weaver et al. 1994); GmZIP1, a zinc transporter (Moreau et al. 2002); GmDMT1, an iron transporter (Kaiser et al. 2003); and GmSAT1 from soybean (Kaiser et al. 1998). GmSAT1 previously was reported as an ammonium transport protein (Kaiser et al. 1998); however, subsequent data indicate that this probably is not the case (Marini et al. 2000).

Relatively little is known about transporters in other plant membranes of developing or mature nodules. Two ammonium transporters of the AMT family, LjAMT1 and LjAMT2, have been cloned from Lotus japonicus and shown to be expressed in nodules (Salvemini et al. 2001; Simon-Rosin et al. 2003). The putative PM location of LjAMT2 indicates that this transporter may be involved in recovering ammonium lost from nodule cells by diffusion (Simon-Rosin et al. 2003). The lack of knowledge about transporters in nodules limits significantly our understanding not only of the long-distance movement of ions and metabolites into and out of nodules, but also of the intracellular transport of these and, by extension, metabolism as a whole.

Expressed-sequence-tag (EST) projects on several legume species, including soybean, Medicago truncatula, and Lotus japonicus, have uncovered many transporter genes that are ex- 
pressed in nodules. In silico and experimental approaches have identified a subset of these genes that are more highly expressed in nodules than in other organs, which may play key roles in SNF (Colebatch et al. 2002; Fedorova et al. 2002; Journet et al. 2002). One of these genes, LjKUP from Lotus spp., which encodes a homolog of KUP/KT/HAK $\mathrm{K}^{+}$transporters, is the focus of this article.

Potassium transporters of the KUP family are encoded by large multigene families in plants (Banuelos et al. 2002; Maser et al. 2001; Rodriguez-Navarro 2000). Although genetics studies have implicated two KUP proteins, AtKUP4/TRH1 and AtKUP2/SHY3, in elongation of root hairs and hypocotyls, respectively (Elumalai et al. 2002; Rigas et al. 2001), the physiological roles of KUP proteins remain largely unknown. The KUP family has not been studied at all in legumes. To gain insight into the possible roles of the nodule-induced KUP in L. japonicus, we cloned a full-length $L j K U P$ cDNA and demonstrated that it encodes a functional potassium transporter by heterologous expression in Escherichia coli. We also measured relative transcript levels of $L j K U P$ in different organs and within nodules during a development time-series. Together with data on the intracellular location of LjKUP, also presented here, the results indicate that KUP proteins play a wider range of roles in plants than previously suspected.

\section{RESULTS}

\section{Isolation and sequence analysis of $L j K U P$.}

Transcriptome analysis of Lotus japonicus uncovered several genes encoding putative transporters that were more highly expressed in nodules than in uninfected roots (Colebatch et al., 2002). One of these, LjNEST8d4, exhibited homology to the KUP family of $\mathrm{K}^{+}$transporters that are present in bacteria, fungi, and plants. Subsequent sequencing of the entire LjNEST8d4 clone revealed a single, large open reading frame (ORF) with a stop near the 3 '-end followed by a polyA tail. No in-frame stop codon was found at the 5'-end of the ORF, which indicated that the clone was probably not a full-length cDNA. This was confirmed by 5'-RACE, which yielded a further 163 nucleotides of up-stream sequence including three in-frame stop codons. To facilitate later functional analysis, a full-length cDNA, named $L j K U P$ was physically reconstructed from the 5'-RACE and EST clones (discussed below).
The full-length $L j K U P$ cDNA (GenBank accession number AY359855) is 2,451 bp long. It encodes a protein of 718 amino acids (aa) with a predicted molecular mass of $80.4 \mathrm{kDa}$ and a PI of 8.77. The encoded protein is highly hydrophobic and is predicted to contain 12 transmembrane domains (Fig. 1). LjKUP has a long hydrophilic C-terminus (208 aa), as well as a large hydrophilic internal loop between predicted transmembrane domains 2 and 3 (63 aa). These features are common to members of the KUP family from $E$. coli (Schleyer and Bakker 1993), Arabidopsis spp., rice, and barley (Banuelos et al. 2002; Maser et al. 2001; Rodriguez-Navarro 2000; Rubio et al. 2000).

The amino acid sequence of LjKUP was compared with all Arabidopsis spp., rice, E. coli, and Mesorhizobium loti KUP homologs. The protein sequences aligned well between amino acids 110 and 604 of LjKUP, but poorly at the N- and Cterminal ends. Therefore, we utilized the central region of the multiple sequence alignment for phylogenetic analysis, which revealed five major subfamilies of KUP-related sequences in higher plants (Fig. 2). Rice contains members of all five subfamilies, whereas Arabidopsis spp. have members in only three (subfamilies III to V). Interestingly LjKUP belongs to a subfamily (I) that contains no Arabidopsis homolog, which appears to have diverged from the prokaryotic lineage before all other plant subfamilies.

\section{LjKUP gene expression analysis.}

Previous work showed that, although $L j K U P$ is expressed in both uninfected roots and nodules of Lotus spp., it is much more highly expressed in the latter (Colebatch et al. 2002). To obtain a more complete picture of the pattern and relative abundance of LjKUP transcripts within Lotus plants, real-time reverse-transcription polymerase chain reaction (RT-PCR) analysis of total RNA isolated from leaves, infected and uninfected roots, and nodules was performed. Using a constitutive Lotus ubiquitin gene to normalize transcript levels, it was found that $L j K U P$ transcript levels were approximately 40-fold higher in nodules than in roots or leaves of 7-week-old plants (Table 1). The amount of LjKUP transcript in entire, nodulated roots was approximately sixfold higher than in uninoculated roots of the same age, which reflected the dilution of nodule RNA by that of roots. To learn more about the regulation of $L j K U P$ expression during nodulation, three mutants of Lotus spp. affected in nodule development were

$$
\begin{aligned}
& \text { MNNNAHRS PPNDVVVNLNVDSATPNNVTGNNKKMI KEKRDTLILAYRTLGVVFGGLVTSP - } 60 \\
& \text { LYVYPSMPLHSPTEEDYLGIYSIIFWTLTLIGVVKYANIAIKADDHGEGGTFAVYSLLCR - } 120 \\
& \text { HFNIGILPSKQQQQQQQLGLNSMTRGTETHTWLAKLFERSVVARRVLLFVAMLGTCMLIG - } 180 \\
& \text { DGILTPAISVLSAMDGVRAPFPKVSKSLVEALSAVVLIFLFLLOKYGTSRVSFLFSPIMG }-240 \\
& \text { AWTLSTPLVGIYSI IHHYPSIFKALSPHYIFRFFLRNGKS GWLLLGGIVLCITGSEAMFA }-300 \\
& \text { DLGHFNPRSIQIAFLFTIYPSLVLTYAGQTAYLIKHPNDHDDGFYKFIPKPVYWPIFTIA }-360 \\
& \text { TLAAVVASOSLISATFS VIKQSVVLDYFPRVKI I HTSHNKEGEVYSPEVNYILMVLCVAV - } 420 \\
& \text { ILIFGDGKDIGNAFGVVVSLVMLITTILLTLVMIMIWRTPAILVSLYFVVEFVMEGVYVS }-480 \\
& \text { AVFTKIAEGGWIPFAISFILAF IMFGWFYGRQRKIDYEVTHKVTFERLQELLSDCSVQRV - } 540 \\
& \text { PGLCFFYTNIQDGLTPILGHYIKNMKSLHKVTIFTTLRYLLVPKVAPHERIVIKKTNLKG - } 600 \\
& \text { VYCCVIQYGYADTPTIARDDFVDQVINSLTTHIQNCSDNGSFDSHEIEEQVSSLEEARCS - } 660 \\
& \text { GVVHVRGKTRFYVGLNCGWFDKIMLGFYEIMHSNCRSGLPALGVSLQHRIEVGMLYEA - } 718
\end{aligned}
$$

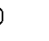


analyzed. The Ljsym6-1 mutant of Lotus spp. is unable to develop normal nodules following inoculation but, instead, produces small bumps on the roots, which are devoid of infection threads (Schauser et al. 1998). The Ljsymll mutant develops pink nodules that abort and turn white relatively quickly (Schauser et al. 1998). The pink color indicates that leghemoglobin synthesis occurs, at least transiently, in these nodules. Nodule development of Ljsymll is blocked at a later stage than in Ljsym6-1 (Schauser et al. 1998). Finally, the harl-1 mutant is defective in feedback regulation of nodulation and, as a result, exhibits a hypernodulation phenotype (Szczyglowski et al. 1998; Wopereis et al. 2000). The Har1 gene encodes a receptor-like kinase homologous to Clavata 1 of Arabidopsis spp. (Krusell et al. 2002). Unlike Ljsym6-1 and Ljsym 11, which are unable to form effective nodules, harl-1 nodules are able to fix nitrogen. Transcript levels of $L j K U P$ did not increase significantly in Ljsym6-1 roots after inoculation with rhizobia. In contrast, LjKUP expression increased in nodulated roots of both harl-1 and Ljsym11 (Table 1). The level of LjKUP transcript in nodulated roots of harl-1 was greater than that of the wild type 7 weeks after inoculation, which probably reflected the greater number of nodules on the mutant. In contrast, LjKUP transcript levels in nodulated Ljsymll roots were not significantly different from those of the wild type.

To test whether nitrogen fixation by bacteroids influences $L j K U P$ expression in nodules, an $M$. loti mutant defective in the regulatory gene, nifA2 was utilized. The mutant elicits nodules on Lotus plants but is unable to fix nitrogen (Clive Ronson, personal communication). LjKUP transcript levels in nodulated roots harboring the nifA2 $2^{-}$strain were similar to those harboring the wild-type rhizobia (Table 1). Thus, maximal expression of $L j K U P$ during nodulation was independent of SNF.

A time-course study of $L j K U P$ transcript levels in inoculated roots was performed to reveal the kinetics of gene induction during nodulation. LjKUP transcript levels remained low and constant for the first 7 days following inoculation with rhizobia (Fig. 3), although nodules were visible as small white bumps on the roots by day 7 . By day 14, however, $L j K U P$ transcript levels had increased approximately fourfold and, by day 21, transcript levels in nodulated roots were 22-fold higher than in the first week. Levels of $L j K U P$ transcript did not change in uninoculated roots of control plants during this time (Fig. 3).

\section{LjKUP functionally complements} an $E$. coli potassium transport mutant.

Potassium transport activity has been demonstrated for several plant KUP homologs expressed either in E. coli or yeast (Banuelos et al. 2002; Elumalai et al. 2002; Fu and Luan 1998; Kim et al. 1998; Quintero and Blatt 1997; Rigas et al. 2001; Rubio et al. 2000; Santa-Maria et al. 1997; Senn et al. 2001). To test whether LjKUP transports $\mathrm{K}^{+}$, we expressed both full-length $L j K U P$ cDNA and the partial cDNA, LjNEST8d4, in E. coli TK2463, which has mutations in three $\mathrm{K}^{+}$transport systems, TRK, KUP, and KDP (Epstein et al.

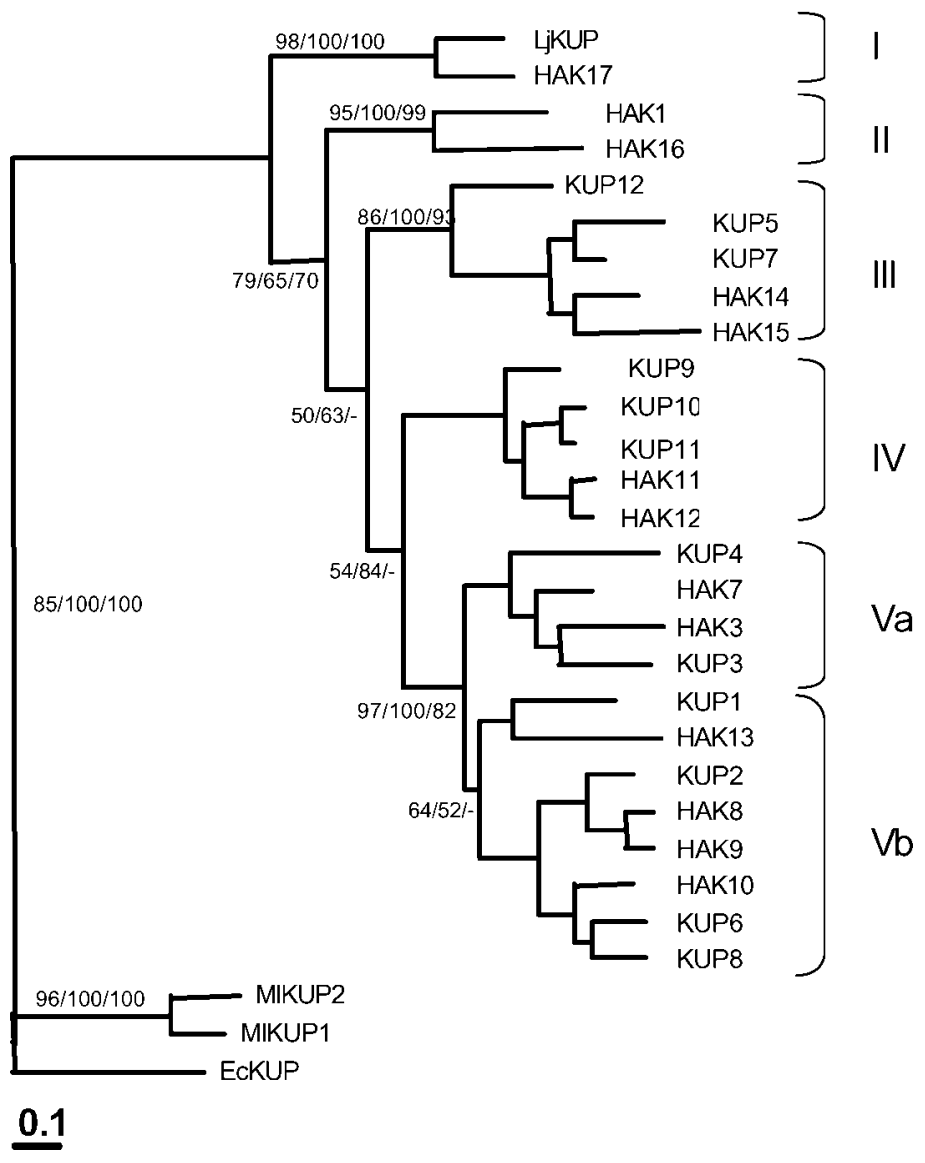

Fig. 2. Phylogenetic tree of plant KUP sequences. The maximum likelihood tree was inferred from comparisons of the LjKUP amino acid sequence (amino acids 110 to 604) and the corresponding region of homologs from Arabidopsis spp. (Maser et al. 2001), rice (Banuelos et al. 2002), Mesorhizobium loti (MIKUP1, accession number NP_103011; MIKUP2, accession number NP_103010), and Escherichia coli (EcKUP, accession number NP_418203). The sequences from E. coli and $M$. loti were used as out-groups. Support values (percent) for the branches were derived from maximum likelihood, neighborjoining bootstrap (1,000 replicates each), and parsimony bootstrap analysis (500 replicates), respectively. The scale bar indicates 10 changes per 100 amino acids. 
1993). Although LjNEST8d4 encodes a slightly truncated LjKUP protein, the protein retains all 12 putative transmembrane domains (Fig. 1). Transcription of cDNA was driven by a lactose-inducible promoter in vector pSPORT1. Expression of both LjKUP and LjNEST8d4 in strain TK2463 increased the growth rate of the mutant in low-potassium liquid LK medium (Kim et al. 1998) supplemented with 0 , 10, or 50 $\mathrm{mM} \mathrm{K}^{+}$(Fig. 4).

\section{LjKUP is located}

in the PM when expressed in Arabidopsis cells.

Various computer programs were used to predict the intracellular location of LjKUP. Both PSORT and Protcomp predicted a PM location for LjKUP. To test this hypothesis, we determined the location of a green fluorescent protein (GFP)LjKUP fusion protein expressed in Arabidopsis cells. Transient expression of the GFP-LjKUP fusion, driven by the CaMV-35S promoter, was achieved in both Arabidopsis leaf epidermal cells and in protoplasts of cell cultures. In both cases, GFP was detected exclusively at the periphery of cells (Fig. 5A and B). Transient expression of KCO1-GFP, a tonoplast marker (Czempinski et al. 2002), resulted in a different pattern of fluorescence: In addition to a peripheral

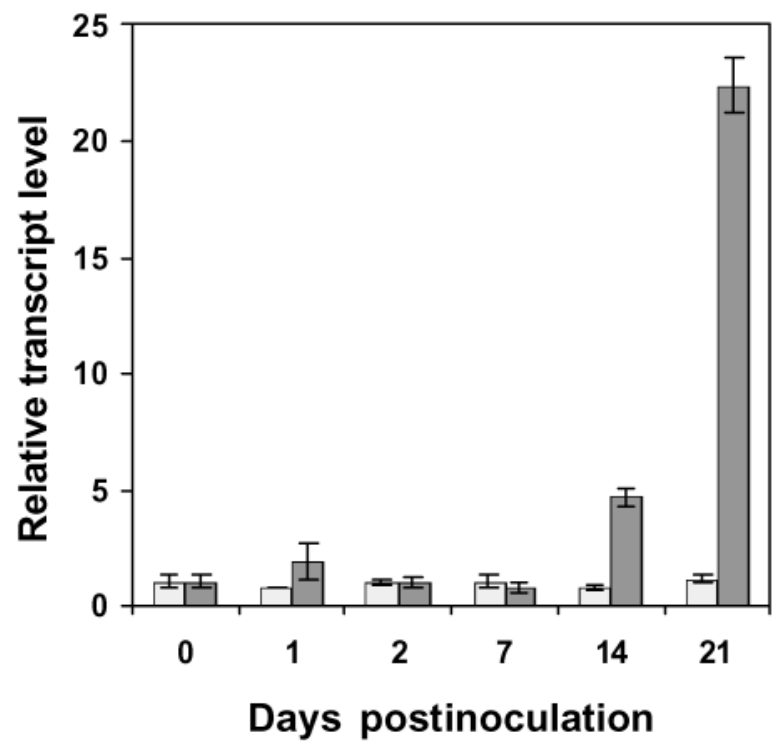

Fig. 3. Kinetics of $L j K U P$ induction during nodule development. Total RNA was extracted from entire root systems 0 to 21 days after inoculation with Mesorhizobium loti, as indicated. LjKUP transcript levels were normalized against those of the constitutively-expressed gene, LjUBI (Colebatch et al. 2002) at each time point, then expressed relative to the level of $L j K U P$ transcript at time zero, as described in Table 1. Data represent mean \pm standard deviation $(n=3)$. location, GFP typically was observed in internal membranes, which presumably lined transvacuolar strands of cytoplasm (Fig. 5C and D). KCO1-GFP also was removed from the cell periphery in places where the nucleus forced the tonoplast aside (data not shown), as described previously (Czempinski et al. 2002). The GFP-LjKUP fusion protein never was observed away from the cell periphery in turgid cells. However, in plasmolyzed cells derived from transformed protoplasts, GFPLjKUP fluorescence surrounded the condensed or shrunken cytoplasm (Fig. 5E and F). Taken together, these data indicate a PM location of LjKUP.

\section{DISCUSSION}

LjKUP is the first legume KUP family member to be characterized. We have shown that, like other KUP proteins, LjKUP transports potassium. However, unlike any other KUP that has been localized in plant cells to date, LjKUP appears to be a PM protein. $L j K U P$ transcripts were found to accumulate substantially late during nodule development, implying that the protein is important for SNF. Taken together, the results indicate that KUP proteins play a more diverse range of roles in plants than suspected previously.

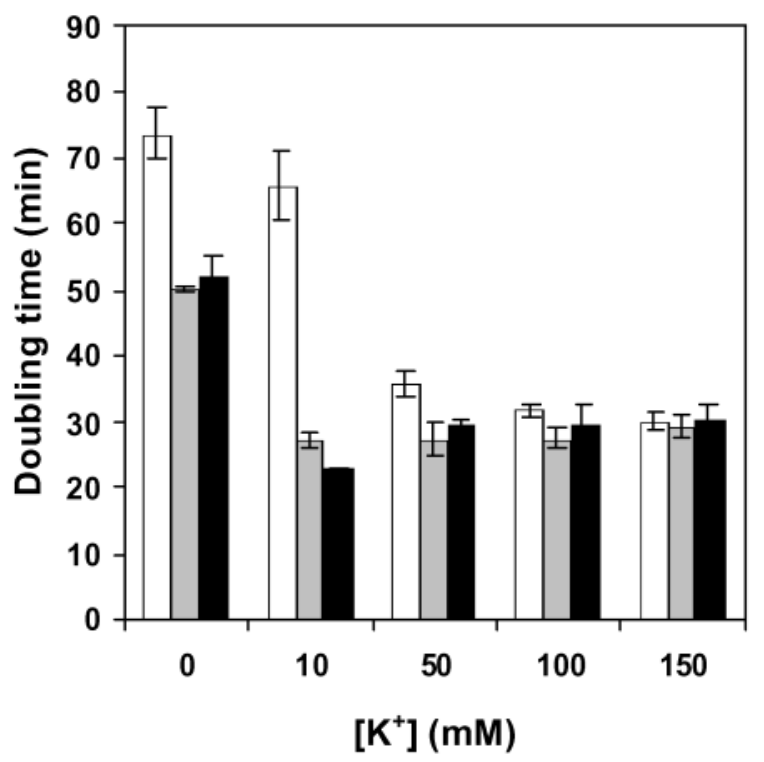

Fig. 4. Functional complementation of Escherichia coli potassium transport mutant, strain TK2463. The mutant strain was transformed with pSPORT containing LjKUP (gray bar), LjNEST8d4 (black bar), or the cloning vector alone (white bar). Cells were grown at $37^{\circ} \mathrm{C}$ in $\mathrm{LK}$ medium containing different concentrations of added $\mathrm{K}^{+}$(indicated). Error bars represent standard deviation from mean doubling times obtained from three independent experiments.

Table 1. $L j K U P$ transcript levels in different organs and genotypes ${ }^{\mathrm{a}}$

\begin{tabular}{|c|c|c|c|c|c|}
\hline \multirow[b]{3}{*}{ Lotus genotype } & \multicolumn{5}{|c|}{ Organ or $M$. loti strain } \\
\hline & \multirow{2}{*}{$\begin{array}{c}\text { Leaves } \\
\text { R7A }\end{array}$} & \multirow{2}{*}{$\begin{array}{c}\text { Nodules } \\
\text { R7A }\end{array}$} & \multicolumn{3}{|c|}{ Roots (with or without nodules) } \\
\hline & & & R7A & Uninoculated & NifA $^{-}$ \\
\hline Wild type & $10.0 \pm 1.5(1.2)$ & $4.8 \pm 1.8$ & $7.6 \pm 2.1(6.1)$ & $10.2 \pm 1.9$ & $7.3 \pm 3.7(7.6)$ \\
\hline harl-1 & $\ldots$ & $\ldots$ & $7.0 \pm 2.5(33)$ & $12.0 \pm 3.4(1)$ & $\ldots$ \\
\hline Ljsym6 & $\ldots$ & $\ldots$ & $11.2 \pm 2.8(0.7)$ & $10.6 \pm 1.2(1)$ & $\ldots$ \\
\hline Ljsym11 & $\ldots$ & $\ldots$ & $7.5 \pm 0.4(4.4)$ & $9.7 \pm 0.31$ & $\ldots$ \\
\hline
\end{tabular}

${ }^{\text {a }}$ Plants were either uninoculated or inoculated with wild-type Mesorhizobium loti (R7A) or with an nifA ${ }^{-}$strain of $M$. loti (NifA ${ }^{-}$) and grown in sand for 7 weeks prior to harvest. $\mathrm{C}_{\mathrm{T}}$ values for $L j K U P$ obtained from real-time reverse-transcription polymerase chain reaction were normalized against those of ubiquitin (yielding $\Delta \mathrm{C}_{\mathrm{T}} \pm$ standard deviation, with at least two biological and two technical replicates in each case). The relative expression level of $L j K U P$ (value in parentheses) was calculated using the formula $X_{\text {fold }}=2^{-(\Delta \mathrm{CtA}-\Delta \mathrm{CtB})}$, with uninoculated roots $\left(\Delta \mathrm{C}_{\mathrm{T}} \mathrm{B}\right)$ used as the reference condition in each genotype. 


\section{Developmental regulation of $L j K U P$.}

Most of the Arabidopsis KUP genes that have been characterized, including the five genes AtKUP1-5, appear to be expressed more or less constitutively throughout plants, which suggests that they are involved in housekeeping functions (Elumalai et al. 2002; Fu and Luan 1998; Kim et al. 1998; Quintero and Blatt 1997; Rigas et al. 2001; Rubio et al. 2000). Massively parallel signature sequencing (MPSS) data for different Arabidopsis organs supports the published expression data for AtKUPl to $A t K U P 5$, inclusive, and indicates that $A t K U P 7$ also is constitu-
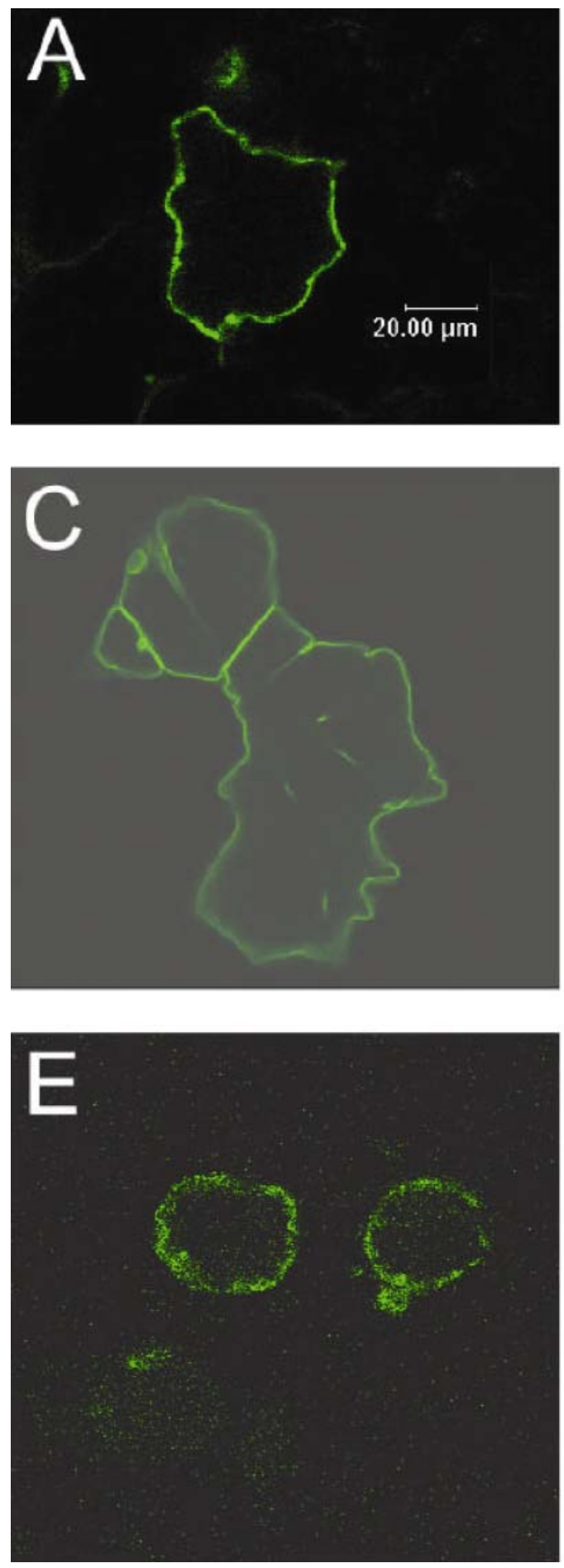

Fig. 5. Green fluorescent protein (GFP)-LjKUP is plasma membrane-located in Arabidopsis spp. GFP-LjKUP was expressed transiently in A and B, Arabidopsis leaf epidermal cells or in $\mathbf{E}$ and $\mathbf{F}$, Arabidopsis cell-culture protoplast. As a control, the tonoplast marker GFP-KCO1 also was expressed transiently in $\mathbf{C}$ and D, Arabidopsis leaf epidermal cells. GFP was detected by confocal microscopy 24 to $48 \mathrm{~h}$ after transformation. Images of green fluorescence obtained under UV light (left panels) were overlayed onto those taken under white light (right panels) to reveal the intracellular location of GFP. 
were 40-fold higher in nodules than elsewhere (Table 1). Induction of LjKUP expression during nodulation (Fig. 3) appeared to be under developmental control: The plant mutant Ljsym6-1, which is blocked at an early stage of nodule development, exhibited no increase in $L j K U P$ transcript following inoculation with rhizobia (Table 1). On the other hand, high levels of $L j K U P$ transcript in nodulated roots of the plant mutant Ljsyml1 inoculated with wild-type rhizobia, and of wild-type plants inoculated with an $M$. loti nifA2- mutant (Table 1), neither of which can fix nitrogen, indicated that LjKUP induction was not dependent on SNF.

The kinetics of $L j K U P$ induction during nodulation (Fig. 3) revealed that the gene is activated late during nodule development, between 7 and 14 days after inoculation with rhizobia, at a time when nodule expansion is maximal. These results provide a clue to one possible physiological role of $\mathrm{LjKUP}$, as discussed below. Sustained, high-level expression of LjKUP in mature, nitrogen-fixing nodules (Fig. 3; Table 1) indicates that LjKUP also plays an important role during SNF.

\section{LjKUP is a potassium transporter.}

Complementation of the E. coli potassium transport mutant, TK2463, by LjKUP showed that the protein from Lotus spp. is able to transport $\mathrm{K}^{+}$. Expression of LjKUP in the mutant reduced its doubling time significantly even with only trace amounts of $\mathrm{K}^{+}$in the medium (i.e., no added $\mathrm{K}^{+}$) (Fig. 4), which indicated that the transporter has a high affinity for $\mathrm{K}^{+}$. Previous work on other plant KUP homologs revealed a range of affinities for $\mathrm{K}^{+}$among this family, including high affinity ( $K_{\mathrm{m}}$ in the micromolar range; AtKUP1 [Kim et al. 1998], HvHAK1 [Santa-Maria et al. 1997], OsHAK1 [Banuelos et al. 1995], AtHAK5 [Rubio et al. 2000]), low affinity (HvHAK2 [Senn et al. 2001]), and both high and low affinities (AtKT1 [Fu and Luan 1998]).

\section{Subcellular location of LjKUP.}

As mentioned above, relatively little is known about the intracellular location of KUP proteins in plants. The rice KUP homolog OsHAK10 was targeted to the tonoplast membrane when expressed as a C-terminal GFP fusion in onion epidermal cells (Banuelos et al. 2002), suggesting that it resides in the same membrane in rice. Despite speculation that other plant KUPs may be located in the PM (Desbrosses et al. 2003; Elumalai et al. 2002; Rodriguez-Navarro 2000; Senn et al. 2001), direct evidence for a PM location has not been published previously.

Thus, the data presented here provide the first experimental evidence that some plant KUPs may reside in the PM. Although fusion of the relatively large GFP molecule to the N-terminal end of LjKUP could have interfered with correct targeting of the protein, it is salient to note that in silico analysis also predicted a PM location for LjKUP.

\section{What is the role or roles of $\mathrm{LjKUP}$ in nodules?}

Potassium is the most abundant cation in higher plants and is crucial for ionic homeostasis, enzyme activity, osmoregulation, and growth (Epstein et al. 1963; Epstein 1966; Kochian and Lucas 1993). Typically, $\mathrm{K}^{+}$concentrations in plant cells $(>100 \mathrm{mM})$ are several orders of magnitude higher than those in the external medium. Transporters and channels in the PM provide the means by which cells accumulate this ion (Brownlee 2002; Zimmermann and Sentenac 1999). We have presented the first direct evidence that plant KUPs may be located in the PM (Fig. 5). Although this result should be confirmed (by immunolocalization in Lotus spp., for instance), it indicates that KUP transporters probably contribute to accumulation of $\mathrm{K}^{+}$across the PM. Consistent with this notion is the observation that LjKUP and related proteins in other species are high-affinity $\mathrm{K}^{+}$transporters, which would enable them to access micromolar concentrations of the ion in the external medium (Fig. 3) (Banuelos et al. 1995; Kim et al. 1998; Rubio et al. 2000; Santa-Maria et al. 1997). Little is known about the mechanism of $\mathrm{K}^{+}$transport by plant KUPs. Consideration of data from fungi and yeast led RodriguezNavarro (2000) to the conclusion that plant KUPs likely function as $\mathrm{K}^{+}-\mathrm{H}^{+}$symporters, which would enable them to accumulate $\mathrm{K}^{+}$to levels that exceed those predicted by the Nernst equation. Thus, KUPs may play an active role in ionic and osmotic homeostasis in cells.

During nodule development, root cortical and pericycle cells undergo substantial expansion (and division), which requires large amounts of $\mathrm{K}^{+}$, not only to maintain ion homeostasis but also to provide turgor pressure for cell growth. Massive induction of LjKUP gene expression during nodulation and the location of the protein in the PM indicate that LjKUP may play an important role in cell expansion during the latter stages of nodule development. Consistent with this idea are observations that KUP homologs in plants are essential for cell and tissue expansion. For instance, the Arabidopsis trh1-1 mutant, which is defective in root-hair elongation, is impaired in AtKUP4 (Rigas et al. 2001), and the shy3-1 mutant, which is defective in stem elongation, is affected in AtKUP2 (Elumalai et al. 2002). A role for KUP proteins in cell elongation also was proposed from work in cotton. Induction of a KUP gene in cotton fiber cells was associated with increased fiber osmotic and turgor potentials, which drove a rapid phase of cell elongation (Ruan et al. 2001).

Continued, high-level expression of LjKUP in mature nodules of Lotus spp. (Table 1), which, because of their determinate nature, cease to grow significantly after maturity, indicates that the protein fulfils additional or alternative functions during SNF. Obviously, $\mathrm{K}^{+}$transporters and channels in the $\mathrm{PM}$ are required throughout the life of a cell, for the reasons mentioned above. For instance, the presence of LjKUP in mature nodule cells may be required to maintain the ionic milieu essential for the biochemical and biophysical processes that underpin symbiotic nitrogen fixation. The amenability of $L$. japonicus to reverse genetics will enable us to test the importance of LjKUP in nodule development and SNF in the future.

\section{MATERIALS AND METHODS}

\section{Biological material.}

L. corniculatus cv. japonicus ecotype GIFU seed were scarified in liquid nitrogen $(3 \times 10 \mathrm{~s})$, sterilized in a $2 \%$ bleach solution for $10 \mathrm{~min}$, rinsed five times with sterile distilled water, and germinated in a petri dish on filter paper soaked with B\&D medium (Broughton and Dilworth 1971). After germination in a phytotron $\left(25^{\circ} \mathrm{C}, 16 \mathrm{~h}\right.$ of light, $8 \mathrm{~h}$ of dark $), 3$-day-old seedlings were transferred to pots (five plants per pot) containing coarse quartz sand and inoculated with $M$. loti R7A. Inoculated plants were grown in a glasshouse with a 16-h day, $60 \%$ relative humidity, and day and night temperatures of 21 and $17^{\circ} \mathrm{C}$, respectively, and watered once per day with $\mathrm{B} \& \mathrm{D}$ medium. Alternatively, 4-day-old seedlings were transferred to square petri dishes containing fresh $\mathrm{B} \& \mathrm{D}$ with $0.1 \mathrm{mM} \mathrm{\textrm {KNO } _ { 3 }}$ and grown in a phytotron $\left(22^{\circ} \mathrm{C}, 16 \mathrm{~h}\right.$ of light, $8 \mathrm{~h}$ of dark) for 3 weeks before being inoculated with $M$. loti NZP2235. Inoculated plants and uninoculated controls then were maintained under the same growth conditions until harvested.

\section{DNA methods and constructs.}

Clone LjNEST8d4 was completely sequenced, using a combination of subcloning and primer-walking, by the company 
AGOWA (Berlin). To obtain the complete LjKUP cDNA sequence, 5' RACE was performed: Total RNA was extracted from 6- to 7-week-old nodules using an RNeasy kit (Qiagen, Hilden, Germany), and cDNA synthesis was performed with Superscript II (Invitrogen, Carlsbad, CA, U.S.A.) using the $L j K U P$-specific primer 5'-CTGGCTAGCAACAACAGCAG$3^{\prime}$. Amplification of the $5^{\prime}$ end of $L j K U P$ cDNA was performed with the 5' RACE PCR kit from Invitrogen following the manufacturer's instructions. The first round of PCR was performed with the abridged anchor primer from the kit and a second $L j K U P$-specific primer (GSP2: 5'-GATTCCCAAATAG TCCTCTTCCGTC-3'). Nested PCR then was performed with the universal primer and a third $L j K U P$-specific primer (GSP3: 5'-GTAAAGCGGCGATGTCACGAGACC-3'). The PCR program used consisted of $2 \mathrm{~min}$ at $95^{\circ} \mathrm{C} ; 35$ cycles of $95^{\circ} \mathrm{C}$ for 15 $\mathrm{s}, 58^{\circ} \mathrm{C}$ for $30 \mathrm{~s}$, and $70^{\circ} \mathrm{C}$ for $1 \mathrm{~min}$; and finally $70^{\circ} \mathrm{C}$ for 10 min. The resulting single PCR product was sequenced commercially by AGOWA.

To reconstruct physically the full-length $L j K U P$ cDNA, the $5^{\prime}$ end of the cDNA was PCR amplified and ligated at the internal SpeI site of LjNEST8d4, as follows. The 5' end of LjKUP was amplified from nodule cDNA using: proofreading Pfu polymerase (Stratagene, La Jolla, CA, U.S.A.); the forward primer, 5'-GGAATTCTGGGCTTCGTTTTCTGTTCT-3', which added an EcoRI restriction site to the $5^{\prime}$ end of the amplicon; and the reverse primer, 5'-GAGTCGACATTGAGG TTGACGA-3', which contained the unique SpeI site of $L j K U P$. The PCR product was separated on an agarose gel and purified using a QIAEX II Gel Extraction Kit (Qiagen). The PCR fragment and LjNEST8d4 clone in pSPORT1 were digested separately with EcoRI, purified, digested with SpeI, purified again, ligated together, and transformed into competent $E$. coli DH5 $\alpha$ cells. The presence of recombinant, full-length $L j K U P$ cDNA in individual transformants was tested by PCR and finally confirmed by sequencing.

Construction of recombinant vector for expression of a GFP-LjKUP fusion protein in Arabidopsis cells was achieved using GATEWAY technology (Invitrogen). LjKUP cDNA was amplified using pfu polymerase, the forward primer 5' GGAATTCTGGGCTTCGTTTTCTGTTCT-3', the reverse primer 5'-CTGGCTAGCAACAACAGCAG-3', and the PCR program consisting of $94^{\circ} \mathrm{C}$ for $2 \mathrm{~min}$, followed by 30 cycles of $94^{\circ} \mathrm{C}$ for $15 \mathrm{~s}, 55^{\circ} \mathrm{C}$ for $30 \mathrm{~s}$, and $72^{\circ} \mathrm{C}$ for $2 \mathrm{~min}$. The forward and reverse primers contained the attB1 and attB2 recombination sites, respectively. The PCR product was recombined into the entry vector pSpectre (B. Trevaskis, unpublished data) using BP clonase enzyme (30 ng of insert, $150 \mathrm{ng}$ of entry vector, $2 \mu \mathrm{l}$ of BP buffer, $1 \mu \mathrm{l}$ of BPclonase in $10 \mu \mathrm{l}$ of final volume; recombination overnight at $25^{\circ} \mathrm{C}$ followed by proteinase $\mathrm{K}$ treatment), and transformed into $E$. coli DH5 $\alpha$. Entry clones containing $L j K U P$ were checked by restriction analysis and by $\mathrm{PCR}$, recombined with the destination vector $\mathrm{pN}-\mathrm{GFP}$ (B. Trevaskis, unpublished data) (150 ng of entry clone, $150 \mathrm{ng}$ of destination clone, $2 \mu \mathrm{l}$ of LR buffer, $4 \mu \mathrm{l}$ of Tris-EDTA, and 1 $\mu \mathrm{l}$ of LRclonase in a final volume of $10 \mu \mathrm{l}$; recombination for $1 \mathrm{~h}$ at $25^{\circ} \mathrm{C}$ followed by proteinase $\mathrm{K}$ treatment), and transformed into DH5 $\alpha$. Positive recombinant clones were screened by restriction analysis, confirmed by PCR, and finally sequenced to verify the correct construction.

\section{Phylogenetic analysis.}

Phylogenetic methods were implemented using the computer program PAUP* (version 4.0b10; Sinauer Associates, Sunderland) for neighbor joining and maximum parsimony, and TreePuzzle (Schmidt et al. 2002) for maximum likelihood analysis. The BLOSUM62 model of amino acid substitutions was used for maximum likelihood inference.

\section{Real-time RT-PCR.}

Harvested plant material was frozen immediately in liquid nitrogen and stored at $-70^{\circ} \mathrm{C}$. Total RNA was extracted from frozen organs of Lotus plants using an RNeasy kit (Qiagen). Prior to cDNA synthesis, 1 to $2 \mu \mathrm{g}$ of total RNA was treated with RNase-free DNaseI (Sigma-Aldrich, St. Louis) to destroy genomic DNA. DNaseI-treated RNA subsequently was phenolchloroform extracted, precipitated, and resuspended in $10 \mu \mathrm{l}$ of water. Reverse transcription then was performed with SuperScript II reverse transcriptase (Invitrogen). Primers to glutathione-S-transferase, which span an intron, were used to confirm absence of genomic DNA. The efficiency of cDNA synthesis was assessed by real-time PCR amplification of ubiquitin, and only those reactions that exhibited similar efficiencies (similar $\mathrm{C}_{\mathrm{T}}$ values for ubiquitin) were analyzed further.

PCR reactions were performed in a 96-well plate with an ABI Prism 5700 Sequence Detection System (Applied Biosystems, Foster City, CA, U.S.A.), using SYBR Green to monitor double-stranded DNA synthesis. A standard PCR reaction contained approximately $4 \mathrm{ng}$ of cDNA template, $12.5 \mu \mathrm{l}$ of Master Mix, $0.75 \mu$ of SYBR Green (EurogenTech, Seraing, Belgium), 7.5 pmol forward and reverse primers, and water to a final volume of $25 \mu$. The following standard thermal profile was used for all PCR reactions: $50^{\circ} \mathrm{C}$ for $2 \mathrm{~min} ; 95^{\circ} \mathrm{C}$ for $10 \mathrm{~min}$; $40 \mathrm{cy}-$ cles of $95^{\circ} \mathrm{C}$ for $15 \mathrm{~s}$ and $60^{\circ} \mathrm{C}$ for $1 \mathrm{~min}$. Data were analyzed using SDS 2.0 software (Applied Biosystems). For quality control, PCR products were run on a $2 \%$ agarose gel to confirm the presence of a single amplicon. The following primers were used to amplify $L j K U P$ cDNA: forward, 5'-CGTTGA TTCTCGCCTACAGGAC-3'; reverse, 5'-TAAAGCGGCGAT GTCACGA-3'). $\mathrm{C}_{\mathrm{T}}$ values for $L j K U P$ were normalized to levels for ubiquitin (Colebatch et al. 2002) before making comparisons between organs.

\section{E. coli complementation studies.}

E. coli TK2463 ( $F_{-}$thi LacZ $Z_{\mathrm{amX82}}$ rha $\Delta($ trkA) trkD1 $\triangle(k d p F A B) 5$ endA) was transformed with pSPORT containing LjKUP or LjNEST8d4 and grown on KML media (Epstein and Kim 1971) supplemented with $50 \mathrm{mM} \mathrm{KCl}$ and ampicillin at $50 \mu \mathrm{g} / \mathrm{ml}$. For growth-curve analysis, cells from an overnight culture were washed and resuspended to an optical density at $600 \mathrm{~nm}\left(\mathrm{OD}_{600}\right)$ of 0.005 in LK liquid media (Kim et al. 1998) supplemented with various concentrations of $\mathrm{KCl}$. Growth of cultures at $37^{\circ} \mathrm{C}$ was monitored hourly by measuring $\mathrm{OD}_{600}$.

\section{Transient expression of LjKUP in Arabidopsis leaves.}

For subcellular localization of the GFP-LjKUP fusion protein, the expression construct was introduced into epidermal cells of Arabidopsis leaves by particle bombardment using a BioRad PDS-1000 (BioRad, Hercules, CA, U.S.A.), as previously described (Hibbert et al. 1998). Transformation of Arabidopsis cell culture protoplasts also was performed using published protocols (Abel and Theologis 1998; Axelos et al. 1992). Imaging of GFP was performed using a Leica confocal scanner TCS SPII together with a Leica DM IRBE microscope (Leica, Bensheim, Germany) 24 to $48 \mathrm{~h}$ after bombardment (Sohlenkamp et al. 2002). KCO1-GFP was used as a tonoplast marker (Czempinski et al. 2002).

\section{ACKNOWLEDGMENTS}

This work was supported by the European Union (HPRN-CT-200000086) and the Max Planck Society. We thank S. Hartmann (MPI-Golm, Germany) for kind help with the phylogenetic analysis, A.-G. FonrougeDesbrosses (MPI-Golm, Germany) for help with transient GFP-expression assays and confocal microscopy, J. Schroeder (University of Californa-San Diego) for the gift of E. coli TK2463, K. Czempinski (University of 
Potsdam) for the gift of the vector containing the KCO1::GFP fusion, and H. Sentenac (INRA Montpellier, France) and C. Wood (MPI-Golm, Germany) for useful discussion and critical reading of the manuscript.

\section{LITERATURE CITED}

Abel, S., and Theologis, A. 1998. Transient gene expression in protoplasts of Arabidopsis thaliana. Methods Mol. Biol. 82:209-217.

Andreev, I. M., Dubrovo, P. N., Krylova, V. V., and Izmailov, S. F. 1999 Functional identification of ATP-driven $\mathrm{Ca}^{2+}$ pump in the peribacteroid membrane of broad bean root nodules. FEBS (Fed. Eur. Biochem. Soc.) Lett. 447:49-52.

Axelos, M., Curie, C., Mazzolini, L., Bardet, C., and Lescure, B. 1992 A protocol for transient expression in Arabidopsis thaliana. Plant Physiol. Biochem. 30:123-128.

Banuelos, M. A., Garciadeblas, B., Cubero, B., and Rodriguez-Navarro, A. 2002. Inventory and functional characterization of the HAK potassium transporters of rice. Plant Physiol. 130:784-795.

Banuelos, M. A., Klein, R. D., Alexander-Bowman, S. J., and RodriguezNavarro, A. 1995. A potassium transporter of the yeast Schwanniomyces occidentalis homologous to the Kup system of Escherichia coli has a high concentrative capacity. EMBO (Eur. Mol. Biol. Organ.) J. 14:3021-3027.

Brewin, N. J. 1993. The Rhizobium-legume symbiosis: Plant morphogenesis in a nodule. Semin. Cell Biol. 4:149-156.

Broughton, W. J., and Dilworth, M. 1971. Control of leghemoglobin synthesis in snakes beans. Biochem. J. 125:1075-1080.

Brownlee, C. 2002. Plant $\mathrm{K}^{+}$transport: Not just an uphill struggle. Curr. Biol. 12:R402-404.

Campos, F., Perez-Castineira, J. R., Villalba, J. M., Culianez-Marcia, F A., Sanchez, F., and Serrano, R. 1996. Localization of plasma membrane $\mathrm{H}^{+}$-ATPase in nodules of Phaseolus vulgaris L. Plant Mol. Biol. 32:1043-1053.

Colebatch, G., Kloska, S., Trevaskis, B., Freund, S., Altmann, T., and Udvardi, M. K. 2002. Novel aspects of symbiotic nitrogen fixation uncovered by transcript profiling with cDNA arrays. Mol. PlantMicrobe Interact. 15:411-420.

Czempinski, K., Frachisse, J. M., Maurel, C., Barbier-Brygoo, H., and Mueller-Roeber, B. 2002. Vacuolar membrane localization of the Arabidopsis 'two-pore' $\mathrm{K}^{+}$channel KCO1. Plant J. 29:809-820.

Day, D. A., Poole, P. S., Tyerman, S. D., and Rosendahl, L. 2001. Ammonia and amino acid transport across symbiotic membranes in nitrogenfixing legume nodules. Cell. Mol. Life Sci. 58:61-71.

Desbrosses, G., Josefsson, C., Rigas, S., Hatzopoulos, P., and Dolan, L. 2003. AKT1 and TRH1 are required during root hair elongation in Arabidopsis. J. Exp. Bot. 54:781-788.

Elumalai, R. P., Nagpal, P., and Reed, J. W. 2002. A mutation in the Arabidopsis KT2/KUP2 potassium transporter gene affects shoot cell expansion. Plant Cell 14:119-131.

Epstein, E. 1966. Dual patterns of ion absorption by plant cells and by plants. Nature 212:1324-1327.

Epstein, E., Rains, D. W., and Elzam, O. E. 1963. Resolution of dua mechanisms of potassium absorption by barley roots. Proc. Natl. Acad. Sci. U.S.A. 49:684-692.

Epstein, W., and Kim, B. S. 1971. Potassium Transport Loci in Escherichia coli K-12. J. Bacteriol. 108:639-644.

Epstein, W., Buurman, E., McLaggan, D., and Naprstek, J. 1993. Multiple mechanisms, roles and controls of $\mathrm{K}^{+}$transport in Escherichia coli. Biochem. Soc. Trans. 21:1006-1010.

Fedorova, E., Thomson, R., Whitehead, L. F., Maudoux, O., Udvardi, M. K., and Day, D. A. 1999. Localization of $\mathrm{H}^{+}$-ATPases in soybean root nodules. Planta 209:25-32.

Fedorova, M., van de Mortel, J., Matsumoto, P. A., Cho, J., Town, C. D., VandenBosch, K. A., Gantt, J. S., and Vance, C. P. 2002. Genome-wide identification of nodule-specific transcripts in the model legume Medicago truncatula. Plant Physiol. 130:519-537.

$\mathrm{Fu}, \mathrm{H}$. H., and Luan, S. 1998. AtKUP1: A dual-affinity $\mathrm{K}^{+}$transporter from Arabidopsis. Plant Cell 10:63-73.

Hibbert, J. M., Linley, P. J., Kahn, M. S., and Gray, C. J. 1998. Transient expression of green fluorescent protein in various plastid types following microprojectile bombardment. Plant J. 16:627-632.

Journet, E. P., van Tuinen, D., Gouzy, J., Crespeau, H., Carreau, V., Farmer, M. J., Niebel, A., Schiex, T., Jaillon, O., Chatagnier, O., Godiard, L., Micheli, F., Kahn, D., Gianinazzi-Pearson, V., and Gamas, P. 2002. Exploring root symbiotic programs in the model legume Medicago truncatula using EST analysis. Nucleic Acids Res. 30:55795592

Kaiser, B. N., Finnegan, P. M., Tyerman, S. D., Whitehead, L. F., Bergersen, F. J., Day, D. A., and Udvardi, M. K. 1998. Characterization of an ammonium transport protein from the peribacteroid membrane of soybean nodules. Science 281:1202-1206.

Kaiser, B. N., Moreau, S., Castelli, J., Thomson, R., Lambert, A., Bogliolo, S., Puppo, A., and Day, D. A. 2003. The soybean NRAMP homologue, GmDMT1, is a symbiotic divalent metal transporter capable of ferrous iron transport. Plant J. 35:295-304.

Kim, E. J., Kwak, J. M., Uozumi, N., and Schroeder, J. I. 1998. AtKUP1: An Arabidopsis gene encoding high-affinity potassium transport activity. Plant Cell 10:51-62.

Kochian, L. V., and Lucas, W. J. 1993. Can $\mathrm{K}^{+}$channels do it all ? Plant Cell 5:720-721

Krusell, L., Madsen, L. H., Sato, S., Aubert, G., Genua, A., Szczyglowski, K., Duc, G., Kaneko, T., Tabata, S., de Bruijn, F., Pajuelo, E., Sandal, N., and Stougaard, J. 2002 Shoot control of root development and nodulation is mediated by a receptor-likekinase. Nature 420:422-6.

LeVier, K., Day, D. A., and Guerinot, M. L. 1996. Iron uptake by symbiosomes from soybean root nodules. Plant Physiol. 111:893-900.

Lodwig, E. M., Hosie, A. H., Bourdes, A., Findlay, K., Allaway, D. Karunakaran, R., Downie, J. A., and Poole, P. S. 2003. Amino-acid cycling drives nitrogen fixation in the legume-Rhizobium symbiosis. Nature 422:722-726.

Long, S R. 2001. Genes and signals in the rhizobium-legume symbiosis. Plant Physiol. 125:69-72.

Marini, A. M., Springael, J. Y., Frommer, W. B., and Andre, B. 2000 Cross-talk between ammonium transporters in yeast and interference by the soybean SAT1 protein. Mol. Microbiol. 35:378-385.

Maser, P., Thomine, S., Schroeder, J. I., Ward, J. M., Hirschi, K., Sze, H., Talke, I. N., Amtmann, A., Maathuis, F. J., Sanders, D., Harper, J. F., Tchieu, J., Gribskov, M., Persans, M. W., Salt, D. E., Kim, S. A., and Guerinot, M. L. 2001. Phylogenetic relationships within cation transporter families of Arabidopsis. Plant Physiol. 126:1646-1667.

Moreau, S., Thomson, R. M., Kaiser, B. N., Trevaskis, B., Guerinot, M L., Udvardi, M. K., Puppo, A., and Day, D. A. 2002. GmZIP1 encodes a symbiosis-specific zinc transporter in soybean. J. Biol. Chem. 277:4738-4746.

Quintero, F. J., and Blatt, M. R. 1997. A new family of $\mathrm{K}^{+}$transporters from Arabidopsis that are conserved across phyla. FEBS (Fed. Eur Biochem. Soc.) Lett. 415:206-211.

Rae, A. L., Bonfante-Fasolo, P., and Brewin, N. J. 1992. Structure and growth of infection threads in the legume symbiosis with Rhizobium leguminosarum. Plant J. 2:385-395.

Rigas, S., Desbrosses, G., Haralampidis, K., Vicente-Agullo, F., Feldmann, K. A., Grabov, A., Dolan, L., and Hatzopoulos, P. 2001. TRH1 encodes a potassium transporter required for tip growth in Arabidopsis root hairs. Plant Cell 13:139-151.

Rivers, R. L., Dean, R. M., Chandy, G., Hall J. E., Roberts, D. M., and Zeidel, M .L. 1997. Functional analysis of nodulin 26, an aquaporin in soybean root nodule symbiosomes. J. Biol. Chem. 272:16256-16261

Roberts, D. M., and Tyerman, S. D. 2002. Voltage-dependent cation channels permeable to $\mathrm{NH}_{4}{ }^{+}, \mathrm{K}^{+}$, and $\mathrm{Ca}^{2+}$ in the symbiosome membrane of the model legume Lotus japonicus. Plant Physiol. 128:370-378.

Rodriguez-Navarro, A. 2000. Potassium transport in fungi and plants. Biochim. Biophys. Acta 1469:1-30.

Ruan, Y. L., Llewellyn, D. J., and Furbank, R. T. 2001. The control of single-celled cotton fiber elongation by developmentally reversible gating of plasmodesmata and coordinated expression of sucrose and $\mathrm{K}^{+}$transporters and expansin. Plant Cell 13:47-60.

Rubio, F., Santa-Maria, G., and Rodriguez-Navarro, A. 2000. Cloning of Arabidopsis and barley cDNAs encoding HAK potassium transporters in root and shoot cells. Physiol. Plant 109:34-43.

Salvemini, F., Marini, A., Riccio, A., Patriarca, E. J., and Chiurazzi, M. 2001. Functional characterization of an ammonium transporter gene from Lotus japonicus. Gene 270:237-243.

Santa-Maria, G. E., Rubio, F., Dubcovsky, J., and Rodriguez-Navarro, A. 1997. The HAK1 gene of barley is a member of a large gene family and encodes a high-affinity potassium transporter. Plant Cell 9:22812289.

Schauser, L., Handberg, K., Sandal, N., Stiller, J., Thykjaer, T., Pajuelo, E., Nielsen, A., and Stougaard, J. 1998. Symbiotic mutants deficient in nodule establishment identified after T-DNA transformation of Lotus japonicus. Mol. Gen. Genet. 259:414-423.

Schleyer, M., and Bakker, E. P. 1993. Nucleotide sequence and 3'-end deletion studies indicate that the $\mathrm{K}^{+}$-uptake protein kup from $E s$ cherichia coli is composed of a hydrophobic core linked to a large and partially essential hydrophilic C-terminus. J. Bacteriol. 175:69256931.

Schmidt, H. A., Strimmer, K., Vingron, M., and von Haeseler, A. 2002. TREE-PUZZLE: Maximum likelihood phylogenetic analysis using quartets and parallel computing. Bioinformatics 18:502-4.

Schultze, M., and Kondorosi, A. 1998. Regulation of symbiotic root nod- 
ule development. Annu. Rev. Genet. 32:33-57.

Senn, M. E., Rubio, F., Banuelos, M. A., and Rodriguez-Navarro, A. 2001. Comparative functional features of plant potassium HvHAK1 and HvHAK2 transporters. J. Biol. Chem. 276:44563-44569.

Simon-Rosin, U., Wood, C., and Udvardi, M. K. 2003. Molecular and cellular characterization of LjAMT2-1, an ammonium transporter from the model legume Lotus japonicus. Plant Mol. Biol. 51:99-108.

Sohlenkamp, C., Wood, C. C., Roeb, G. W., and Udvardi, M. K. 2002. Characterization of Arabidopsis AtAMT2, a high-affinity ammonium transporter of the plasma membrane. Plant Physiol. 130:1788-1796.

Stougaard, J. 2000. Regulators and regulation of legume root nodule development. Plant Physiol. 124:531-540.

Szczyglowski, K., Shaw, R. S., Wopereis, J., Copeland, S., Hamburger, D., Kasiborski, B., Dazzo, F. B., and de Bruijn, F. J. 1998. Nodule organogenesis and symbiotic mutants of the model legume Lotus japonicus. Mol. Plant-Microbe Interact. 11:684-697.

Tyerman, S. D., Whitehead, L. F., and Day, D. A. 1995. A channel-like transporter for $\mathrm{NH}_{4}^{+}$on the symbiotic interface of $\mathrm{N}_{2}$-fixing plants. Nature 378:629-632.

Udvardi, M. K., and Day, D. A. 1997. Metabolite transport across symbiotic membrane of legume nodules. Annu. Rev. Plant Physiol. Plant Mol. Biol. 48:493-523.

Udvardi, M. K., Lister, D. L., and Day, D. A. 1991. ATPase activity and anion transport across the peribacteroid membrane of isolated soybean symbiosomes. Arch. Microbiol. 156:362-366.

Udvardi, M. K., Price, G. D., Gresshoff, P. M., and Day, D. A. 1988. A di- carboxylate transporter on the peribacteroid membrane of soybean nodules. FEBS (Fed. Eur. Biol. Soc.) Lett. 231:36-40.

Verma, D. P., and Hong, Z. 1996. Biogenesis of the peribacteroid membrane in root nodules. Trends Microbiol. 4:364-368.

Weaver, C. D., Shomer, N. H., Louis, C. F., and Roberts, D. M. 1994 Nodulin 26, a nodule-specific symbiosome membrane protein from soybean, is an ion channel. J. Biol. Chem. 269:17858-17862.

Wopereis, J., Pajuelo, E., Dazzo, F. B., Jiang, Q., Gresshoff, P. M., De Bruijn, F. J., Stougaard, J., and Szczyglowski, K. 2000. Short root mutant of Lotus japonicus with a dramatically altered symbiotic phenotype. Plant J. 23:97-114.

Zimmermann, S., and Sentenac, H. 1999. Plant ion channels: From molecular structures to physiological functions. Curr. Opin. Plant Biol. 2:477-482.

\section{AUTHOR-RECOMMENDED INTERNET RESOURCES}

The Center for Biological Seequence Analysis TMHMM prediction server: www.cbs.dtu.dk

The Institute for Genetic Research (TIGR) gene indices: www.tigr.org/tdb/tgi/plant.shtml

MPSS Arabidopsis database: mpss.ucdavis.edu/java.html

PSORT database for the prediction of protein sorting signals and localization sites: psort.nibb.ac.jp

Softberry bioinformatics Protcomp software: www.softberry.com 